\begin{tabular}{ll|l}
\cline { 2 - 2 } Case Reports in & \multicolumn{2}{l}{ Case Rep Ophthalmol 2016;7:216-222 } \\
\cline { 2 - 3 } & $\begin{array}{l}\text { 10.1159/000445496 } \\
\text { Publisned onIne: April 29, 2016 }\end{array}$ & $\begin{array}{l}\text { P 2016 The Author(s) } \\
\text { Published by S. Karger AG, Basel } \\
1663-2699 / 16 / 0071-0216 \$ 39.50 / 0 \\
\text { www.karger.com/cop }\end{array}$ \\
\cline { 2 - 3 } & $\begin{array}{l}\text { This article is licensed under the Creative Commons Attribution-NonCommercial } 4.0 \\
\text { International License (CC BY-NC) (http://www.karger.com/Services/OpenAccessLicense). } \\
\text { Usage and distribution for commercial purposes requires written permission. }\end{array}$
\end{tabular}

\title{
Chronic Inflammation in an Anophthalmic Socket due to a Room Temperature Vulcanized Silicone Implant
}

\author{
Alicia Galindo-Ferreiro ${ }^{a, b}$ Laila AlGhafri ${ }^{a} \quad$ Sahar M. Elkhamary ${ }^{a, c}$ \\ Azza Maktabi $^{a} \quad$ Alberto Gálvez-Ruiz ${ }^{a}$ Julio Galindo-Alonso ${ }^{d}$ \\ Silvana Schellini Proff ${ }^{a}$ e \\ ${ }^{a}$ King Khaled Eye Specialist Hospital, Umm Al Hamam Al Gharbi, Riyadh, Saudi Arabia; \\ ${ }^{b}$ Department of Ophthalmology, Complejo Asistencial Palencia, Palencia, Spain; \\ 'Department of Diagnostic Radiology, Mansoura Faculty of Medicine, Mansoura, Egypt; \\ ${ }^{d}$ Rio Hortega University Hospital, Valladolid, Spain; ${ }^{e}$ Department of Ophthalmology, \\ Faculdade de Medicina de Botucatu - UNESP, Botucatu, Brazil
}

\section{Keywords}

Chronic inflammation · Orbital implant · Inflammation · Orbit · Silicone

\begin{abstract}
Two case reports are used to illustrate the signs and symptoms, complications and treatments of chronic socket inflammation due to intraorbital implants. The ophthalmic examination, surgeries and treatments are documented. Two anophthalmic cases that underwent enucleation and multiple orbital surgeries to enhance the anophthalmic socket volume developed pain, intense discharge and contracted cavities with chronic inflammation in the socket which was nonresponsive to medical therapy. Computed tomography indicated a hypodense foreign body in both cases causing an intense inflammatory reaction. The implants were removed by excisional surgery and a room temperature vulcanized silicone implant was retrieved in both cases. Socket inflammation resolved in both cases after implant removal. An intraorbital inflammatory reaction against an intraorbital implant can cause
\end{abstract}




\section{Case Reports in Ophthalmology}

chronic socket inflammation in patients with a history of multiple surgeries. Diagnosis requires imaging and the definitive treatment is implant removal.

(c) 2016 The Author(s)

Published by S. Karger AG, Basel

Some eye diseases or severe trauma can result in an anophthalmic socket requiring the replacement of the orbit volume for acceptable cosmesis. However, complications of anophthalmic socket reconstruction include dehiscence, extrusion, implant migration, contracture of the socket, and chronic inflammation $[1,2]$. An acute or chronic inflammatory reaction can occur secondary to the placement of an implant used to repair the cavity, or of spherical implants or of implants used to reconstruct the orbital walls $[3,4]$. However, these are rare causes of chronic inflammation in an anophthalmic socket and represent a diagnostic challenge. In these cases, careful imaging studies with computed tomography (CT) are helpful and may affect the final treatment decision.

We present the first two case reports in the English peer-reviewed literature of chronic socket inflammation secondary to the placement of a Silastic ${ }^{\circledR} \mathrm{E}$ room temperature vulcanized (RTV) silicone rubber base implant (Dow Corning, Midland, Mich., USA) more than 20 years ago, used to improve the volume in the orbit.

\section{Case Reports}

Case 1

A 56-year-old female was referred to Oculoplastics at the King Khaled Eye Hospital (KKESH) due to complaints of continuous pain and discharge in the right socket that had begun 4 months prior to presentation. The patient had a history of perforating trauma followed by phthisis bulbi in the right eye when she was 3 years old, and she underwent enucleation without placement of an orbital implant a few years later. When she was 35 years old, she underwent surgery for the placement of an RTV silicone subperiosteal implant in the right orbit to improve the socket volume. Ptosis repair was carried out at the age of 37 years, dermis fat graft at the age of 47 years, and a mucous membrane graft and deepening sutures to improve the cul-de-sac at the age of 52 years.

On examination, she had a bulging dystopic external prosthesis and the eyelids did not close properly. The socket was inflamed, grade 3 , with mild redness and copious discharge (fig. 1; upper row). There were no signs of pyogenic granuloma or giant papillary conjunctivitis on examination. The examination of the left eye was unremarkable. The patient was treated with neomycin, bacitracin and dexamethasone drops (Maxitrol; Allergan Inc., Dublin, Ireland) with no benefit. A CT scan of the orbit showed dense material along the extraconal space of the right orbital cavity adjacent to the right orbital roof and lateral wall with rarefaction along the inner layer and minimal hyperostosis (fig. 1; lower row).

The patient underwent surgical excisional biopsy of the foreign body through a crease approach. During the surgery, we found that the material was surrounded by a hard pseudocapsule with the consistency of bone and inflammatory tissue.

Case 2

A 48-year-old male was referred to the KKESH due to complaints of pain, copious discharge, redness, contracted cavity and poorly fitting prosthesis in the left eye. The patient had been involved in a road traffic accident when he was 28 years old. He underwent enu- 
cleation of the left eye without placement of a spherical implant in the left socket. Subsequently, multiple surgeries were performed for socket reconstruction followed by mucous membrane graft, deepening sutures, implantation of a secondary polymethyl methacrylate implant and, later, removal thereof due to dehiscence and exposure, as well as pyogenic granuloma excision.

On examination, the right eye was normal. Examination of the left eye and ocular adnexa indicated an anophthalmic cavity with a grade 4 contracted socket, inflammation, with significant discharge and redness. The patient was unable to hold the prosthesis. Pyogenic granuloma and giant papillary conjunctivitis were ruled out.

The patient was treated with corticosteroids resulting in temporary improvement with recurrence after tapering the steroid. CT scan and magnetic resonance imaging (MRI) indicated an irregular foreign body located in the left orbital roof, associated with adjacent inflammatory changes involving the extraocular muscles (fig. 2). The patient underwent orbital implant removal. A rubber-like foreign body was identified and removed after removal of the surrounding bony layer (fig. 3).

\section{Discussion}

The clinical symptoms of both our cases at presentation were pain, copious discharge, intense inflammation, redness and a contracted socket. Also, both patients had a history of multiple surgeries to correct the chronic problems in the anophthalmic socket.

The chronic discharge in both patients was related to an intense chronic inflammation in the orbital tissues. This is a very common symptom in patient with an anophthalmic cavity likely due to various causes including dry socket (common in sockets because of the absent corneal reflex), incomplete blink, meibomian gland inflammation, giant papillary conjunctivitis (mechanical damage from the external prosthesis to the conjunctiva and hypersensitivity to proteins deposited over the prosthesis), implant exposition or pyogenic granuloma (secondary to suture or implant exposure) [2].

Both patients complained about pain, which may be due to chronic inflammation in the socket. Alternatively, pain may be due to 'phantom eye syndrome' that can occur in one third of anophthalmic cavity carriers as a result of the interruption of the sensory nerves impulse, due to the reorganization of the neurosensory cortex, or due to the regenerative sprouting of the axons resulting in a neuroma [2].

In the current study, both patients presented with contracted cavities with chronic inflammation of the socket related to progressive contraction of the anophthalmic cavity, often associated with the presence of myofibroblast, a modified fibroblast linked to the contracted sockets $[5,6]$.

One of the primary goals of anophthalmic socket treatment is the restoration of an adequate orbital volume through the use of appropriately sized spherical alloplastic implants. Complications of all types of implants can result in discharge, implant exposure, conjunctival thinning, pyogenic granuloma formation, implant infection, with persistent pain or discomfort [7].

Notably, the two cases reported here did not receive a spherical implant in the anophthalmic socket, but a Silastic ${ }^{\circledR E}$ RTV silicone rubber base for volume replacement in the anophthalmic socket. This is a biomaterial which can be used in the orbital floor, lateral wall and roof [8]. The RTV silicone rubber base is a brand injectable silicone rubber elastomer, considered to be a biologically inert, nontoxic, nonreactive thermally stable elastomer, which 
Case Reports in
Ophthalmology

Case Rep Ophthalmol 2016;7:216-222

$10.1159 / 000445496$

www.karger.com/cop

Galindo-Ferreiro et al.: Chronic Inflammation in an Anophthalmic Socket due to a Room Temperature Vulcanized Silicone Implant

is resistant to oxidation and vulcanizes at room temperature [8]. RTV silicone with a catalyst was placed in a dissected pocket subperiosteally along orbital walls to correct the volume deficit in both cases, vulcanizing the implant in situ into soft silicone rubber and conforming the implant to the orbital wall $[9,10]$.

In the current cases, CT studies imaged the implant as a foreign body, which was confirmed by MRI in 1 patient. The image examination is imperative for visualizing the implant and the surrounding inflammatory reaction.

The RTV implant was placed in both patients a few years after the enucleation, and they developed inflamed and contracted sockets with poor cosmetic results. However, good outcomes without complications have been reported with this implant [11-13]. The most important difference between our cases and the literature is the duration of follow-up. Our cases had the implant inserted 21 years (case 1) and 20 years (case 2) ago, which represents the longest follow-up for RTV implants. Hence, long-term follow-up is fundamental to understand the biocompatibility of the implants, as complications such as rejection and subsequent infection, cellulitis, or migration of the material could occur with any type of implants over the lifetime of the patient [4].

We do not know why the previous surgeons opted to use subperiosteal instead of spherical implants to replace socket volume in both patients. Both patients had fat atrophy, deep socket, superior sulcus atrophy and poor cosmesis with the prosthesis due to the sunken cavity.

Other common complications related to silicone implants include hemorrhage, infection, periorbital cellulitis, migration, extrusion, skin fistulae, and sino-orbital fistulae. The index of suspicion should be high when there is persistent conjunctival inflammation despite topical antimicrobial drops, discomfort on palpation of the implant, and pyogenic granuloma [13].

Some have reported that locally all the silicone implants (injectable, sheets or blocks) induce a limited foreign body reaction, which may result in a fibrous pseudocapsule around the implant with the possibility of contraction, leading to migration of the implant $[3,12]$, with the possibility of chronic inflammation secondary to the presence of the silicone orbital implant [14]. In the current cases, the chronic inflammation resolved in both patients after the removal of the implants. If, at some point, an implant was placed, chronic inflammation indicates that implant removal is warranted and lifetime follow-up is required [14, 15].

In conclusion, our cases presented with chronic inflammation in an anophthalmic socket due to a foreign body reaction against the injectable silicone RTV implant. This is a very rare presentation. Anophthalmic cavity carriers presenting with recurrent inflammation have to be investigated according to their previous orbital surgeries and the type of implants. Orbital imaging is helpful in localizing the cause and determining treatment, such as implant removal.

\section{Acknowledgements}

None of the authors have commercial associations (e.g. consultancies, stock ownership, equity interest, patent/licensing arrangements, etc.) that might be perceived as a conflict of interest in connection with this study. 
Case Reports in
Ophthalmology

Case Rep Ophthalmol 2016;7:216-222 $10.1159 / 000445496$

C 2016 The Author(s). Published by S. Karger AG, Basel www.karger.com/cop

Galindo-Ferreiro et al.: Chronic Inflammation in an Anophthalmic Socket due to a Room Temperature Vulcanized Silicone Implant

\section{Statement of Ethics}

The authors have no ethical conflicts to disclose.

\section{Disclosure Statement}

The authors received no financial support for this study and have no financial or proprietary interest in the materials presented in this study.

\section{References}

-1 Paris GL, Spohn WG: Correction of enophthalmos in the anophthalmic orbit. Ophthalmology 1980;87:1301-1308.

-2 Bohman E, Roed Rassmusen ML, Kopp ED: Pain and discomfort in the anophthalmic socket. Curr Opin Ophthalmol 2014;25:455-460.

- 3 Nitsche T, Yousefpour A, Bainton R: Chronic orbital infection caused by migration of an orbital Silastic implant. Int J Oral Maxillofac Surg 2008;37:90-92.

4 Jordan DR, Brownstein S, Faraji H: Clinicopathologic analysis of 15 explanted hydroxyapatite implants. Ophthal Plast Reconstr Surg 2004;20:285-290.

5 Kaltreider SA: The myofibroblast and the anophthalmic socket. Adv Ophthalmic Plast Reconstr Surg 1992;9:93-96.

6 Kaltreider SA, Wallow IH, Gonnering RS, Dortzbach RK: The anatomy and histology of the anophthalmic socket - is the myofibroblast present? Ophthal Plast Reconstr Surg 1987;3:207-230.

7 Buchanan AG, Holds JB, Vagefi MR, Bidar M, McCann JD, Anderson RL: Anterior filler displacement following injection of calcium hydroxylapatite gel (Radiesse) for anophthalmic orbital volume augmentation. Ophthal Plast Reconstr Surg 2012;28:335-337.

-8 Conn H, Tenzel D, Schou K: Subperiosteal volume augmentation of the anophthalmic socket with RTV silastic. Adv Ophthalmic Plast Reconstr Surg 1990;8:220-228.

-9 Vistnes LM, Paris GL: Uses of RTV silicone in orbital reconstruction. Am J Ophthalmol 1977;83:577-581.

$\$ 10$ Vistnes LM, Paris GL: Uses of RTV silicone in orbital reconstruction. 1977. Adv Ophthalmic Plast Reconstr Surg 1990;8:214-219.

11 Sergott TJ, Vistnes LM: Correction of enophthalmos and superior sulcus depression in the anophthalmic orbit: a long-term follow-up. Plast Reconstr Surg 1987;79:331-338.

-12 Nasr AM, Jabak MH, Batainah Y: Orbital volume augmentation with subperiosteal room-temperaturevulcanized silicone implants: a clinical and histopathologic study. Ophthal Plast Reconstr Surg 1994;10:11-21; discussion 22-23.

13 Owji N, Sadeghipour A, Salour H, Sahraeyan N: Pyogenic granuloma as a presenting sign of hydroxyapatite orbital implant exposure: a clinicopathologic study. Ophthal Plast Reconstr Surg 2006;22:467-471.

$\checkmark 14$ Joseph S, Cheung D: Late orbital floor implant migration presenting as recurrent episcleritis. Orbit 2014;33:132-134.

15 Lee DH, Joo YE, Lim SC: Migrated orbital silastic sheet implant mimicking bilateral sinusitis. J Craniofac Surg 2011;22:2158-2159. 


\section{Case Reports in Ophthalmology}
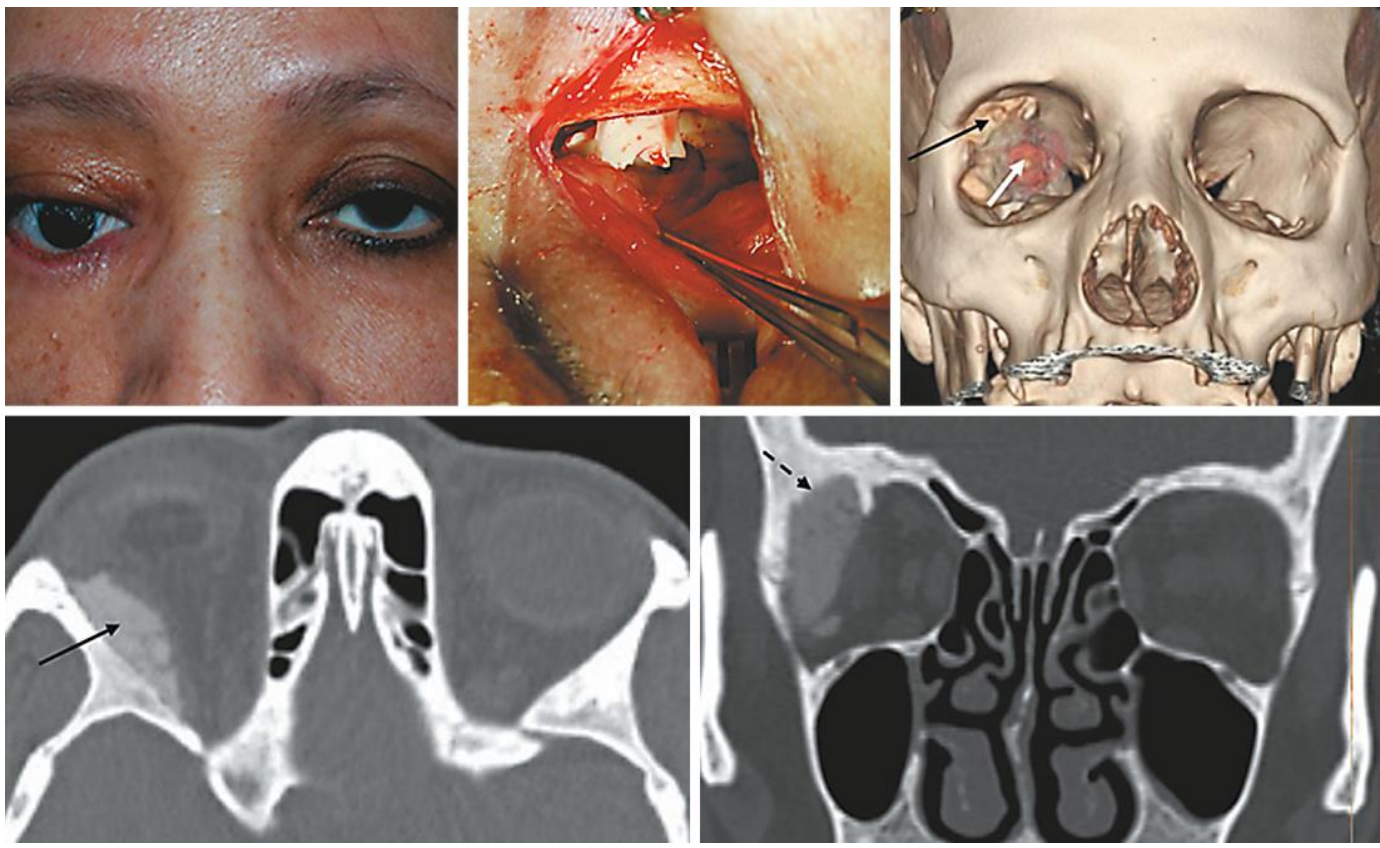

Fig. 1. Case 1. Upper row, left: dystopic prosthesis and poor cosmesis before surgery. Upper row, middle: intraoperative finding of the RTV silicone implant removed by the skin crease approach. Upper row, right: the findings are confirmed in a colored 3D reformation of the surface-shaded image (the white arrow indicates the implant and the black arrow indicates the silastic material). Lower row: the axial and coronal CT scan (bone window) shows dense material along the extraconal space of the right orbital cavity adjacent to the right orbital roof and lateral orbital wall (black arrow) with rarefaction along the inner table and minimal hyperostosis (dashed black arrow). 


\section{Case Reports in Ophthalmology}

\begin{tabular}{l|l}
\hline Case Rep Ophthalmol 2016;7:216-222 \\
\hline $10.1159 / 000445496$ & $\begin{array}{l}\text { @ 2016 The Author(s). Published by S. Karger AG, Basel } \\
\text { www.karger.com/cop }\end{array}$ \\
\hline
\end{tabular}

Galindo-Ferreiro et al.: Chronic Inflammation in an Anophthalmic Socket due to a Room Temperature Vulcanized Silicone Implant
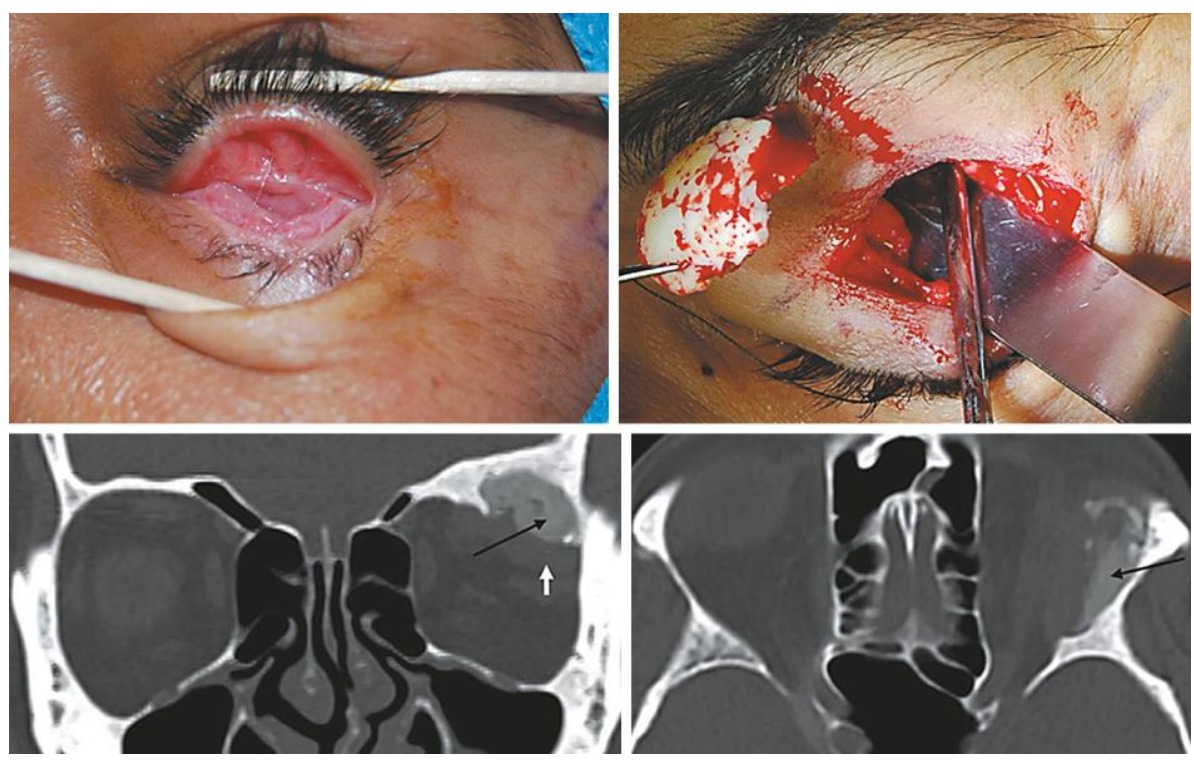

Fig. 2. Case 2. Upper row, left: preoperative status of the socket (grade 4, inflamed, contracted). Upper row, right: intraoperative RTV orbital implant, removed by the skin crease approach. Lower row: coronal and axial CT scan (bone window) showing a dense irregular mass originating from left orbital roof muscles (black arrow), associated with adjacent inflammatory changes in the extraocular muscles (white arrow).
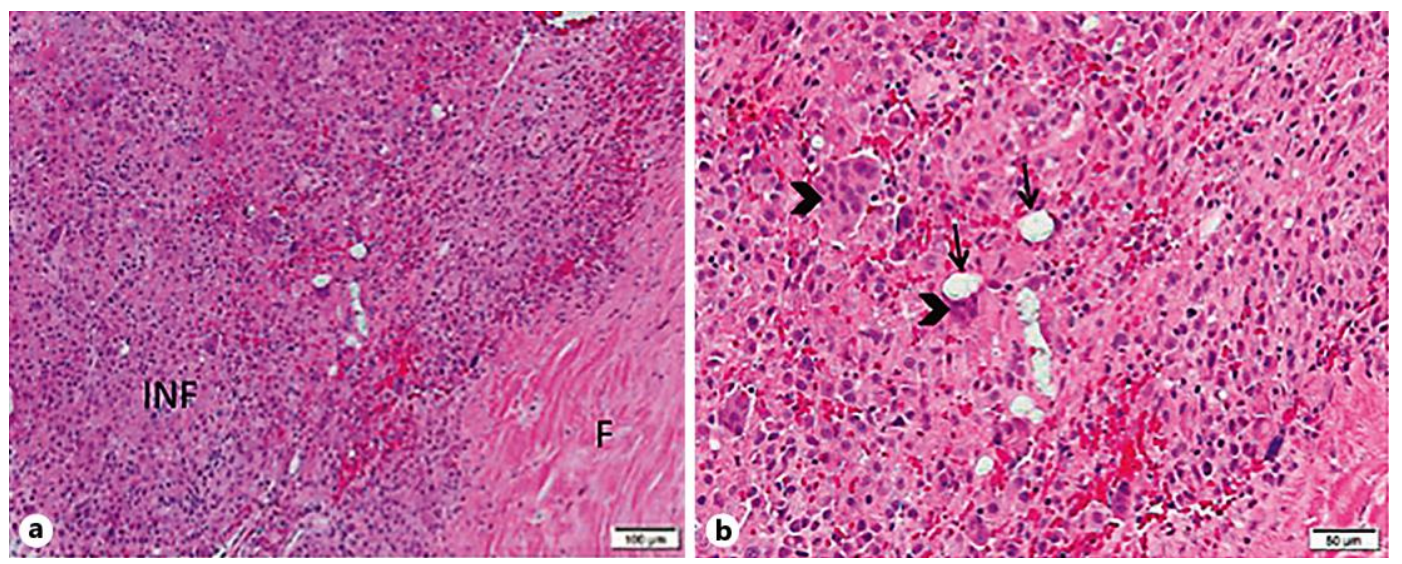

Fig. 3. Pathology slides; tissue around the orbital foreign body. a Fibrosis (F) and granulomatous inflammation (INF) surrounding an empty vacuoles. $H \& E \times 10$. b Empty vacuoles (arrow) surrounded by histiocytes and foreign body giant cells (arrowhead). $\mathrm{H} \& \mathrm{E} \times 20$. 